\title{
Blood Transfusion Practice in Critically III Patients: A Single Institutional Experience
}

\author{
Lama Al-Faris $^{a} \quad$ Abdul Rahman Al-Fares $^{b} \quad$ Kefaya Abdul Malek $^{\mathrm{b}} \quad$ Alaa Omran $^{\mathrm{a}}$ \\ Salah Al-Humood ${ }^{\mathrm{c}}$ \\ ${ }^{a}$ Hematology Unit, Department of Laboratory Medicine, and bepartment of Intensive Care and Anaesthesia, \\ Al-Amiri Hospital, Ministry of Health, Sharq, and ' Department of Pathology, Faculty of Medicine, Health Sciences \\ Centre, Kuwait University, Jabriya, Kuwait
}

\section{Key Words}

Anemia $\cdot$ Critically ill patients $\cdot$ Red cell transfusion

\begin{abstract}
Objectives: To assess the transfusion practice in the intensive care unit (ICU) in a general hospital in Kuwait relative to indications, pretransfusion hemoglobin, red blood cell (RBC) use and outcome. Subjects and Methods: 475 patients were admitted to the ICU during the study period (January 2009 to February 2010). Ninety-nine received RBC transfusion. Demographic, clinical and transfusion data were prospectively collected for the 99 patients who were followed up for 30 days, until hospital discharge, or death, whichever occurred first. Indications for RBC transfusion included hemorrhage in 39 patients, improving oxygen-carrying capacity in 55, and hemolysis in 5. Results: Of the 99 transfused patients, 22 $(22.22 \%)$ were also transfused after discharge from the ICU. Transfusions were more frequent in patients admitted with respiratory failure $(30,30.3 \%)$, hemorrhagic shock $(24,24.2 \%)$, and septic shock $(18,18.4 \%)$. The mean pretransfusion hemoglobin in ICU transfusions was statistically different (70.9 $\pm 12.7 \mathrm{~g} / \mathrm{l})$ from transfusions after discharge $(79.7 \pm 9.4 \mathrm{~g} / \mathrm{l})$ ( $p<0.001)$. Longer ICU stay was associated with more RBC units transfused per transfusion episode per patient $(p<$
\end{abstract}

0.001). The Sequential Organ Failure Assessment (SOFA) score was significantly associated with the number of RBC units transfused per patient $(p=0.006)$. Mortality was significantly associated with Acute Physiology and Chronic Health Evaluation II and SOFA scores, the need and duration for mechanical ventilation, and the length of stay in hospital. Conclusion: Intensivists in our center followed a restrictive transfusion practice, by adopting a low pretransfusion hemoglobin threshold. Decisions on RBC transfusions seemed in most cases to be based on a 'transfusion trigger' rather than a physiologic need.

Copyright $\odot 2012$ S. Karger AG, Basel

\section{Introduction}

Anemia is common in critically ill patients. Most patients are anemic on admission to the intensive care unit (ICU), and among the few patients who have normal hemoglobin levels at presentation, nearly all become anemic during the course of their stay in the ICU $[1,2]$. Several mechanisms are responsible for the development of anemia in critically ill patients, the most important of which are blood loss and blunted erythropoietic activity [3-5].

\section{KARGER}

Fax +41613061234

E-Mail karger@karger.ch

www.karger.com
(C) 2012 S. Karger AG, Basel

1011-7571/12/0216-0560\$38.00/0

Accessible online at:

www.karger.com/mpp
Dr. Salah Al-Humood

Department of Pathology, Faculty of Medicine

Health Sciences Centre, Kuwait University

PO Box 24923, Safat 13110 (Kuwait)

E-Mail salhumood@hsc.edu.kw 
Red blood cell (RBC) transfusion, which helps maintain adequate oxygen delivery, is the typical treatment for anemia despite the well-recognized risks $[6,7]$. Studies of transfusion practices in both US and Western European ICUs indicate that nearly one half of all critically ill patients receive allogeneic blood transfusions $[2,8]$. As reported by Corwin et al. [3], when the ICU stay is $>1$ week, the transfusion incidence reaches $85 \%$, virtually ensuring that the most severely ill patients will be exposed to allogeneic blood during their stay in the ICU.

It is common practice to maintain the hemoglobin level above $100 \mathrm{~g} / \mathrm{l}$ in the critically ill, probably because high oxygen-carrying capacity and oxygen delivery is important in preventing tissue hypoxia and organ failure $[3,9]$. This practice has been influenced by clinical trials which showed that maintaining supra-normal oxygen delivery in patients with established critical illness does not change outcome; however, a large, randomized trial in Canadian ICUs provided strong evidence that anemia is well tolerated by critically ill patients, and that liberal transfusion with non-leukodepleted RBC transfusion to maintain hemoglobin levels of $>100 \mathrm{~g} / \mathrm{l}$ is associated with higher mortality in some patients $[10,11]$.

We therefore carried out a prospective observational cohort study to assess transfusion practice in the ICU of a general hospital in Kuwait relative to indications, pretransfusion hemoglobin level and RBC use in critically ill patients. We also aimed to examine the relationship between anemia and RBC transfusion to clinical outcome.

\section{Subjects and Methods}

\section{Patients and Setting}

This is a prospective, single-center, observational study of ICU patients, in a 15-bed ICU of Al-Amiri Hospital, Kuwait, that has an annual admission rate of $400-480$ patients. This study's enrollment period was from January 2009 to February 2010, in which 475 patients were admitted to the ICU. The 2 consultants practicing in the unit were not following a protocol for specific transfusion triggers covering all patients, since there was no institutional transfusion protocol in place at the time of the study. All admitted patients, who remained in the ICU for $\geq 24 \mathrm{~h}$ and who received $\mathrm{RBC}$ transfusions during the study period were enrolled. Patients were followed for either 30 days or until hospital discharge or death if these occurred before day 30 .

\section{Data Collection}

The following data were collected: patient demographics, admitting diagnostic categories, co-morbidities, ICU admission Acute Physiology and Chronic Health Evaluation II (APACHE II) score, ICU admission Sequential Organ Failure Assessment (SOFA) score, RBC transfusions, pretransfusion hemoglobin levels, mortality, ventilator days, ICU and hospital length of stay, and clinical complications related to transfusion episodes. A transfusion episode was defined as the transfusion event in which the patient receives blood transfusion regardless of the number of $\mathrm{RBC}$ units received per episode. Transfusion practice during the study period was described in terms of transfusion indications and frequency (three groups of indications were specified: hemorrhage, improve $\mathrm{O}_{2}$-carrying capacity, hemolysis), and pretransfusion hemoglobin level. RBC usage for each of the three indications was calculated.

\section{Statistical Analysis}

Data were analyzed using IBM SPSS Statistics, v. 19. Quantitative variables were analyzed using descriptive statistics, including measures of location (mean for symmetrical variables and median for skewed variables). Means are represented as \pm SD, and medians are reported with their interquartile ranges (25th and 75th). Bivariate distribution was evaluated for normality using standard statistical methods and by examining distribution plots. Parametric and nonparametric measures of comparison were used for symmetrical and skewed variables, respectively. Comparisons were tested using the independent-sample $t$ test. Correlations were tested using standard statistical methods depending on the type of outcome measures and the type of predictors. Significance for main effects was tested at the $\alpha=0.05$ level. The associations between various patient characteristics and mortality in the ICU and the patient's odds of dying because of these factors were determined through logistic regression.

\section{Results}

\section{Patient Characteristics}

Of the 475 patients admitted, 99 (21\%) were transfused while in the ICU. Of the 99 patients, 22 (22.22\%) were also transfused after discharge from the ICU. All transfused patients had an ICU stay of $\geq 24 \mathrm{~h}$. The 99 patients demonstrated APACHE II and SOFA scores that were consistent with the high level of illness severity which characterizes typical ICU populations. The demographics of the patients, diagnostic categories on admission and co-morbidities are summarized in table 1 . The mean age of the patients was $57.2 \pm 17.7$ years; $27(27.2 \%)$ were $>70$ years old, and $30(30.3 \%)$ were $<50$ years of age. The mean ICU length of stay was $10.2 \pm 9.5$ days (range: $1-30) ; 27$ (27.2\%) remained in the ICU for $\leq 3$ days, $41(41.4 \%) \geq 1$ week, and $25(25.2 \%)$ stayed for $\geq 2$ weeks. Seventy-seven (74.7\%) patients required mechanical ventilatory support during their ICU stay; the mean duration of mechanical ventilation was $6.2 \pm 8.5$ days (range: $0-30$ ) for ventilated patients. The ICU mortality rate was $24.2 \%$.

\section{Indications for Transfusion}

All 99 patients received at least one unit of RBC transfusion during their ICU stay. Of these, 39 (39.4\%) received 
$\geq 1$ transfusion for hemorrhage, $55(55.6 \%) \geq 1$ transfusion to improve oxygen-carrying capacity, and 5 (5.1\%) for hemolysis. The 55 patients who received transfusion episodes to improve oxygen capacity included those with coronary artery disease, respiratory failure, chronic renal impairment, myelodysplastic syndrome, septic shock, and postoperative patients. The pretransfusion indications and transfusion parameters of ICU patients are summarized in table 2 .

\section{Baseline Hemoglobin Level}

The mean pretransfusion hemoglobin was $70.9 \pm 12.7$ g/l (range: $31-102$ ) on admission and $79.7 \pm 9.4 \mathrm{~g} / \mathrm{l}$ (range: 63-105) after transfusion upon discharge from the ICU; the difference was statistically significant $(\mathrm{p}<0.001)$. The pretransfusion hemoglobin level did not have clinically meaningful differences or any significant associations with age, sex, diagnostic category, APACHE II, or baseline SOFA score.

\section{RBC Transfusion}

The RBC transfusion parameters of transfused patients in the ICU and after ICU discharge are summarized in table 3. A total of $428 \mathrm{RBC}$ units were transfused during the study period, including $388 \mathrm{RBC}$ units in the ICU and 40 after discharge. Fifty-four (54.4\%) patients received their first transfusion within the first $24 \mathrm{~h}$ of admission, with a median time to first transfusion of 0 days (median: 0.0 ; lower quartile: 0.0 ; upper quartile: 4.0 ) for all patients admitted to the ICU. Each patient received a median of 3 RBC units per ICU admission (table 3). Longer ICU stays were associated with more $\mathrm{RBC}$ units per transfusion episode per patient $(\mathrm{p}<0.001)$, but not with pretransfusion hemoglobin levels $(\mathrm{p}=0.57)$. Approximately $2 \%$ of $\mathrm{RBC}$ transfusions were associated with transfusion-related complications. The most common transfusion-related complications reported were fever (1\%) and allergic reaction (1\%). There was no association between the total number of RBC units transfused and age, admitting diagnosis, co-morbidities or pretransfusion hemoglobin levels.

\section{APACHE II and SOFA}

The mean baseline APACHE II and SOFA scores were $23.5 \pm 7.3$ and $6.7 \pm 3.3$, respectively. There was a significant association between SOFA score on admission to the ICU and the number of RBC units transfused per patient $(\mathrm{p}<0.006)$; however, no significant association was found between APACHE II score on admission to the ICU and the number of RBC units transfused per patient $(\mathrm{p}=0.40)$.
Table 1. Characteristics of the 99 patients studied

\begin{tabular}{|c|c|}
\hline Mean age $\pm S D$, years & $57.2 \pm 17.7$ \\
\hline \multicolumn{2}{|l|}{ Gender, $\mathrm{n}(\%)$} \\
\hline Male & $44(44.4)$ \\
\hline Female & $55(55.6)$ \\
\hline \multicolumn{2}{|l|}{ Admission characteristics, mean $\pm \mathrm{SD}$} \\
\hline Pretransfusion Hb level, g/l & $70.88 \pm 12.7$ \\
\hline Admitting SOFA score for first $24 \mathrm{~h}$ in ICU & $6.7 \pm 3.3$ \\
\hline Admitting APACHE II score & $23.5 \pm 7.3$ \\
\hline Days to first transfusion ${ }^{\mathrm{a}}$ & $0(0,4 ; 0-30)$ \\
\hline \multicolumn{2}{|l|}{ Outcome } \\
\hline Length of stay in ICU, days ${ }^{\mathrm{a}}$ & $5(3,15 ; 1-30)$ \\
\hline Length of stay in hospital, days, mean \pm SD & $19 \pm 10$ \\
\hline Died in ICU, n (\%) & $24(24.2)$ \\
\hline Alive in ICU, $\mathrm{n}(\%)$ & $75(75.8)$ \\
\hline \multicolumn{2}{|l|}{ Admitting diagnostic category, n (\%) } \\
\hline Respiratory failure & $30(30.3)$ \\
\hline Hemorrhagic shock & $24(24.2)$ \\
\hline Sepsis/septic shock & $18(18.4)$ \\
\hline Trauma & $9(9.0)$ \\
\hline Cardiovascular & $7(7.1)$ \\
\hline Metabolic acidosis & $2(2.0)$ \\
\hline Multiorgan failure & $1(1.0)$ \\
\hline Others & $8(8.0)$ \\
\hline \multicolumn{2}{|l|}{ Co-morbid condition, $\mathrm{n}(\%)$} \\
\hline No co-morbid conditions & $20(20.4)$ \\
\hline Hypertension & $50(50.0)$ \\
\hline Diabetes & $48(48.8)$ \\
\hline Cardiac disease & $26(26.0)$ \\
\hline Chronic renal impairment & $19(19.0)$ \\
\hline Pulmonary disease & $10(10.0)$ \\
\hline Primary hematological disease & $7(7.0)$ \\
\hline Immunological disease & $3(3.0)$ \\
\hline Chronic liver disease & $12(12.0)$ \\
\hline Others & $10(10.0)$ \\
\hline
\end{tabular}

Some patients had more than one transfusion.

a Expressed as median (1st and 3rd quartile; range).

\section{Mortality in the ICU}

The mortality rate was $24.2 \%$. It was significantly associated with APACHE II score $(\mathrm{p}=0.006)$, SOFA score $(\mathrm{p}=0.001)$, the need for mechanical ventilation $(\mathrm{p}=$ $0.001)$, the duration of mechanical ventilation $(\mathrm{p}<0.5)$, and the length of hospital stay ( $\mathrm{p}=0.001)$. However, age, admitting hemoglobin level, ICU length of stay, and number of RBC units transfused were not associated with mortality rate. There was no dose-response relationship between the number of RBC units transfused and mortality $(\mathrm{p}=0.68)$. 
Table 2. Pretransfusion indications and number of transfusions in the ICU

\begin{tabular}{lcllll}
\hline Indication & $\mathrm{n}(\%)$ & $\begin{array}{l}\text { Pretransfusion } \\
\mathrm{Hb}, \mathrm{g} / \mathrm{l} \\
\text { mean } \pm \mathrm{SD}\end{array}$ & $\begin{array}{l}\text { Transfusion } \\
\text { episodes } \\
\mathrm{n}(\%)\end{array}$ & $\begin{array}{l}\mathrm{RBC} \text { units } \\
\text { transfused } \\
\mathrm{n}(\%)\end{array}$ & $\begin{array}{l}\text { Average number of RBC units } \\
\text { per transfusion episode }\end{array}$ \\
\hline All patients studied & $99(100)$ & $70.9 \pm 12.7$ & 215 & 388 & $1(1,2 ; 1-14)$ \\
Hemorrhage & $39(39.4)$ & $70.4 \pm 14.4$ & $68(31.6)$ & $208(53.6)$ & $2(1.5,4 ; 1-14)$ \\
Improve $\mathrm{O}_{2}$-carrying capacity & $55(55.6)$ & $71.9 \pm 11.1$ & $135(62.8)$ & $167(43.0)$ & $1(1,1 ; 1-4.5)$ \\
Hemolysis & $5(5.1)$ & $63.0 \pm 15.4$ & $12(5.6)$ & $13(3.4)$ & N/A \\
\hline
\end{tabular}

N/A = Not analyzed.

a Expressed as median (1st and 3rd quartile; range).

Table 3. Parameters of transfused patients in ICU and after discharge from the ICU

\begin{tabular}{|c|c|c|c|}
\hline Parameters & $\begin{array}{l}\text { ICU } \\
(n=99)\end{array}$ & $\begin{array}{l}\text { Post-ICU } \\
(\mathrm{n}=22)\end{array}$ & $\mathrm{p}$ value \\
\hline Total number of RBC units transfused per patient & $3(2,5 ; 1-18)^{\mathrm{a}}$ & $0.4 \pm 0.9$ & 0.01 \\
\hline Pretransfusion hemoglobin, g/l & $70.9 \pm 12.7$ & $79.7 \pm 9.4$ & $<0.001$ \\
\hline Days to first transfusion & $0(0,4 ; 0-30)^{\mathrm{a}}$ & N/A & - \\
\hline Number of transfusion episodes per patient & $2.2 \pm 1.9$ & $0.3 \pm 0.8$ & $<0.01$ \\
\hline Average number of $\mathrm{RBC}$ units transfused per episode & $1(1,2 ; 1-14)^{\mathrm{a}}$ & $0.24 \pm 0.45$ & 0.22 \\
\hline Total number of RBC units transfused & 388 & 40 & - \\
\hline
\end{tabular}

N/A = Not analyzed.

a Expressed as median (1st and 3rd quartile; range).

\section{Discussion}

We have shown that our patients in the ICU received $\mathrm{RBC}$ transfusion based on a restrictive transfusion strategy, with a transfusion frequency of $21 \%$, and a mortality rate of $24.2 \%$ during the period of the study.

Anemia was very common in our patients; the mean admission hemoglobin level was $70.9 \pm 12.7 \mathrm{~g} / \mathrm{l}$, as anemia has been reported to be very common in critically ill patients [1]. The demographic and illness-severity data in this study indicated that our patients were admitted with high illness severity, associated with significant organ failure, and were therefore typical of our ICU patient population. However, our data are not directly comparable to other ICUs with a different case mix since there were no cardiac surgery or neurointensive care patients as these were admitted to units in separate subspecialty hospitals.

Despite the frequency of anemia in the ICU, no recent, formal guidelines exist to help clinicians. This resulted in a variable transfusion practice. For example, a Canadian survey revealed that many intensivists perform transfu- sions at hemoglobin levels of approximately $90 \mathrm{~g} / \mathrm{l}$ with a wide variability in practice [12]. A more recent European prospective, observational study documented that anemia was common in critically ill patients, with nearly one third of patients having hemoglobin concentrations of $<100 \mathrm{~g} / \mathrm{l}$. Approximately $40 \%$ of the cohort received transfusions during the course of their ICU stay, and the mean pretransfusion hemoglobin level was $84 \mathrm{~g} / 1$ [1]. A similar study in the United Kingdom confirmed these observations [13]. Unlike other cross-sectional studies, we observed that RBC transfusions in our study were less frequent than previously reported (21 vs. $40-50 \%)[1,2$, 14]. The frequency of RBC transfusions in euvolemic patients for indications other than active bleeding (55\%) was less than what was previously reported in several studies $[3,14]$.

Although there was no institutional protocol for specific transfusion triggers covering all patients, we have shown that the mean RBC transfusion threshold in our ICU was $70.8 \mathrm{~g} / \mathrm{l}$, which indicates that our practice uses conservative transfusion thresholds in most patients. 
This is in keeping with the recommendation of the Transfusion Requirements in Critical Care (TRICC) study; however, our transfusion threshold was lower than that of several other European and Australian studies in which the transfusion practice was not as restrictive as the TRICC study protocol $[1,11,12,15]$.

There was no significant variation in pretransfusion hemoglobin levels, which suggests that the transfusion behavior seemed to be based on the trigger rather than the indication, as reported in several previous studies [2, 3]. Such a practice might be an effective strategy to lower the frequency and amount of blood transfusion [16-19]. The pretransfusion hemoglobin level in our study is the lowest among the thresholds used in ICU practice since the publication of the TRICC study, and therefore, represents successful implementation of evidence-based transfusion practice into the complex ICU clinical setting [1, $2,11,14,20]$. It was also noticed that those patients who were transfused following their discharge from the ICU had a pretransfusion hemoglobin level trigger significantly higher than that adopted in the ICU. This practice could be related to the liberal transfusion practice that is commonly adopted in medical and surgical wards. In view of the lack of an institutional transfusion protocol, however, this practice did not allow us to document the duration of anemia after discharge from the ICU, or the factors that influence it. The frequency of transfusionrelated complications was very low in the present study, probably due to the use of leukocyte-depleted cellular blood components.

The mortality rate in our study was slightly higher than that reported in the TRICC study but similar to oth- er previous reports $[11,21]$. Mortality rates differed significantly by organ failure, consistent with previous reports [1]. However, unlike mortality rates in the TRICC study, mechanically ventilated patients in our study were more likely to die compared to those who were not ventilated. Ventilation increased the risk of dying by a factor of 1.46; however, patients' variables were not matched.

There was no significant association between mortality rates and pretransfusion hemoglobin level. Also, a significant dose-response relationship with increasing mortality rates was not observed as the number of transfusion episodes or RBC units transfused increased. Studies have reported conflicting data regarding the relation of blood transfusion to mortality, with some studies suggesting increased $[1,2,11]$ and others suggesting decreased [22, 23] short-term mortality with transfusion. More recent reports suggest that blood transfusions may no longer be associated with increased mortality rates and may be associated with improved survival $[20,24,25]$. Possible explanations of these discrepancies include the use of leukocyte-depleted cellular blood products and the adoption of a restricted transfusion strategy. A randomized controlled study will be needed to confirm these findings.

\section{Conclusion}

Intensivists in our center followed a restrictive transfusion practice, by adopting a low pretransfusion hemoglobin threshold. Decisions on RBC transfusions appear in most cases to be based on a 'transfusion trigger' rather than a physiologic need.

\section{References}

$>_{1}$ Vincent JL, Baron JF, Reinhart K, Gattinoni L, Thijs L, Webb A, Meier-Hellmann A, Nollet G, Peres-Bota D: Anemia and blood transfusion in critically ill patients. JAMA 2002; 288:1499-1507.

$>2$ Corwin HL, Gettinger A, Pearl RG, Fink MP, Levy MM, Abraham E, Macintyre NR, Shabot MM, Duh MS, Shapiro MJ: The CRIT study: anemia and blood transfusion in the critically ill; current clinical practice in the United States. Crit Care Med 2004;32:39-52.

$\checkmark 3$ Corwin HL, Parsonnet KC, Gettinger A: $\mathrm{RBC}$ transfusion in the ICU. Is there a reason? Chest 1995;108:767-771.

4 Corwin HL, Krantz SB: Anemia of the critically ill: 'acute' anemia of chronic disease. Crit Care Med 2000;28:3098-3099. $\checkmark 5$ Rogiers P, Zhang H, Leeman M, Nagler J, Neels H, Mélot C, Vincent JL: Erythropoietin response is blunted in critically ill patients. Intensive Care Med 1997;23:159-162.

$\checkmark 6$ Busch MP, Kleinman SH, Nemo GJ: Current and emerging infectious risks of blood transfusions. JAMA 2003;289:959-962.

$\checkmark 7$ Perrotta PL, Snyder EL: Non-infectious complications of transfusion therapy. Blood Rev 2001;15:69-83.

8 National Blood Data Resource Center: Report on blood collection and transfusion in the United States in 1999. Available at: http:// www.aabb.org/about_the_aabb/nbdrc/research/bloodsurv.htm

-9 Marini JJ: Transfusion triggers and Occam's rusty razor. Crit Care Med 1998;26:17751776 .
10 Heyland DK, Cook DJ, King DF, Kernerman PF, Brun-Buisson C: Maximizing oxygen delivery in critically ill patients: a methodologic appraisal of the evidence. Crit Care Med 1996;24:517-524.

-11 Hebert PC, Wells GF, Blajchman MA, Marshall JF, Martin CF, Pagliarello GF, Tweeddale M, Schweitzer I, Yeltsir E: A multicenter, randomized, controlled clinical trial of transfusion requirements in critical care. Transfusion Requirements in Critical Care Investigators, Canadian Critical Care Trials Group. N Engl J Med 1999;340:409-417.

-12 Hebert PC, Wells G, Martin C, Tweeddale M, Marshall J, Blajchman M, Pagliarello G, Schweitzer I, Calder L: A Canadian survey of transfusion practice in critically ill patients. Crit Care Med 1998;26:482-487. 
13 Rao MP, Boralessa H, Morgan C, Soni N, Goldhill DR, Brett SJ, Boralessa H, Contreras $\mathrm{M}$ : Blood component use in critically ill patients. Anaesthesia 2002;57:530-534.

14 Chohan SS, McArdle F, McClelland DBL, Mackenzie SJ, Walsh TS: Red cell transfusion practice following the Transfusion Requirements in Critical Care (TRICC) study: prospective observational cohort study in a large UK intensive care unit. Vox Sang 2003;84: 211-218.

15 French CJ, Bellomo R, Finfer SR, Lipman J, Chapman M, Boyce NW: ANZICS Clinical Trials Group: Appropriateness of red blood cell transfusion in Australasian intensive care practice. Med J Aust 2002;177:548-551.

16 Burnum JF: Medical vampires. N Engl J Med 1986;314:1250-1251.
17 Smoller BR, Kruskall MS, Horowitz GL: Reducing adult phlebotomy blood loss with the use of pediatric-sized blood collection tubes. Am J Clin Pathol 1989;91:701-703.

18 Peruzzi WT, Parker MA, Lichtenthal PR, Cochran-Zull C, Toth B, Blake M: A clinical evaluation of a blood conservation device in medical intensive care unit patients. Crit Care Med 1993;21:501-506.

19 The Association of Anaesthetists of Great Britain and Ireland: Blood Transfusion and the Anaesthetist. Available at http://www. aagbi.org/guidelines.html.

20 Engoren M, Arslanian-Engoren C: Longterm survival in the intensive care unit after erythrocyte blood transfusion. Am J Crit Care 2009;18:124-131.

21 Hebert PC, Wells G, Marshall J, Martin C, Tweeddale M, Pagliarello G, Blajchman M: Transfusion requirements in critical care, a pilot study. JAMA 1995;273:1439-1444.
22 Wu WC, Rathore SS, Wang Y, Radford MJ, Krumholz HM: Blood transfusion in elderly patients with acute myocardial infarction. $\mathrm{N}$ Engl J Med 2001;345:1230-1236.

23 Hébert PC, Wells G, Tweeddale M, Martin C, Marshall J, Pham B, Blajchman M, Schweitzer I, Pagliarello G: Does transfusion practice affect mortality in critically ill patients? Transfusion Requirements in Critical Care (TRICC) Investigators and the Canadian Critical Care Trials Group. Am J Respir Crit Care Med 1997;155:1618-1623.

24 Vincent JL, Sakr Y, Sprung C, Harboe S, Damas P: Are blood transfusions associated with greater mortality rates? Results of the Sepsis Occurrence in Acutely Ill Patients study. Anesthesiology 2008;108:31-39.

25 Barz D, Reinhart K: Anemia and blood transfusion in a surgical intensive care unit. Crit Care 2010;14:R92. 